\title{
Enactivism, action and normativity: a Wittgensteinian analysis
}

\author{
Manuel Heras-Escribano', Jason Noble ${ }^{2}$ and Manuel de Pinedo'
}

\begin{abstract}
In this paper, we offer a criticism, inspired by Wittgenstein's rule-following considerations, of the enactivist account of perception and action. We start by setting up a non-descriptivist naturalism regarding the mind and continue by defining enactivism and exploring its more attractive theoretical features. We then proceed to analyse its proposal to understand normativity non-socially. We argue that such a thesis is ultimately committed to the problematic idea that normative practices can be understood as private and factual. Finally, we offer a characterization of normativity as an essentially social phenomenon and apply our criticisms to other approaches that share commitments with enactivism.
\end{abstract}

\section{Keywords}

Enactivism, normativity, Wittgenstein, action, perception, descriptivism

\section{Introduction}

The reports of the death of Cartesianism in the philosophy of mind and of cognitive science have been greatly exaggerated. The Cartesian understanding of mind has three prominent features and an implicit background assumption. The features are: minds are made of nonphysical stuff, minds have privileged, infallible access to their contents and minds are representational organs. Dualism, the claim that mind and matter are different substances, already came into attack in Descartes' times and it is difficult to find dualists in the contemporary scene. Incorrigibility received its due by psychology from its 19th-century origins. Representationalism, however, is still the dominant view regarding mind and cognition. Functionalists in the philosophy of mind and cognitivists in psychology are well known, and amply criticized, examples of representationalist approaches. On the other hand, since the 1970s, antirepresentationalism has become an umbrella term for philosophers that draw their inspiration from Wittgenstein, phenomenology, classical American pragmatism, ecological psychology, and the work of Donald Davidson and Wilfrid Sellars. Richard Rorty's Philosophy and the Mirror of Nature is the most influential book within this tradition (Rorty, 1979). However, with the exception of J. J. Gibson's groundbreaking work on affordances, until the crystallization of enactivism, anti-representationalism mainly remained a negative doctrine. Enactivism has finally put forward a positive alternative to representationalism to understand mindfulness, cognition, perception and agency. We applaud this move and greet the growing heterodox consensus that enactivist thinkers are managing to achieve around their approach.

Enactivism is a new paradigm for explaining life, cognition, and the relation between the two (Stewart, Gapenne, \& Di Paolo, 2010). This approach to cognition is not a straightforward theory. Rather, it is a family of theories based on mutually supporting core concepts such as self-stability, self-assembly, sensemaking, embodiment, emergence, autopoiesis, agency and action-perception (Thompson \& Stapleton, 2009). ${ }^{1}$

We can classify the different enactive theories into two major groups: first, there is an enactive approach for explaining what it is to be a living being, accompanied by an account of perception and action taken as biological processes. Among the authors espousing this first type of enactivism we can find early philosophers such as Jonas (1968) or Maturana and Varela (1980). More recent developments in this tradition by Di Paolo (2005), Barandiaran, Di Paolo, \& Rohde (2009) and Barandiaran and Egbert (2013) join theoretical premises with results from computational and robotic

\footnotetext{
'Departamento de Filosofía I, Universidad de Granada, Granada, Spain

${ }^{2}$ School of Electronics and Computer Sciences, University of

Southampton, Southampton, UK
}

\section{Corresponding author:}

Manuel de Pinedo, Departamento de Filosofía I, Universidad de Granada, I807I, Granada, Spain.

Email: pinedo@ugr.es 
models in order to provide a naturalist explanation of the connection between life and mind. The second major enactive approach is often related to perception. Perception and sensation are not rigidly demarcated in the enactive approach to perception, and this is why we can find a sensorimotor account of taste (Noë, 2004), smell (Cooke \& Myin, 2011) or touch (O'Regan, 2011). Also, the enactive approach has been used to make explicit how this enactive or sensorimotor account provides new ways of understanding informational content (Hutto \& Myin, 2013). As we said, we share the main theoretical drive, away from representations, with both groups, but our criticisms will be centred on some theses put forward by the first group. Section 2 of this paper offers a detailed account of the aspects of enactivism that we find more attractive. Section 3.1 provides the philosophical background needed to put our criticisms in context. Section 3.2 is the core of this paper: in it we make use of Wittgenstein's arguments in favour of the intrinsically social character of normativity to challenge the idea that non-social agents do establish and follow norms or rules (we use both terms interchangeably following the standard philosophical custom). Sections 4 and 5 sketch some ideas about future work and offer a conclusion. The rest of this introduction is a brief summary of the ideas that we will explain in section 3.1.

Our point of departure is the following: once that the three central features of Cartesianism are rejected, there is still a background assumption made by Descartes and only questioned by some philosophers of language and mind in the 20th century: the idea that all our vocabulary, all our explanatory practices, all our attempts at making sense of reality, have a descriptive, factual character. There must be something (some fact, some property, some event) that makes true our statements, whether they are physical, biological, logical, epistemological or ethical. This descriptivist prejudice is, itself, a form of representationalism, this time regarding language. The truth or falsity of a sentence depends on their being or not a corresponding, the fact that the sentence aims at describing. Even Rorty, who coined the term 'anti-representationalism', felt under this linguistic trap. ${ }^{2}$ Most varieties of naturalism are descriptivist-cum-factualist in this sense. What makes them naturalist is their refusal to accept non-natural, spectral, spooky facts. The facts that make true or false our normative evaluations must be just plain, natural facts, those disclosed by the natural sciences.

However, this is far from being the only kind of naturalism. In section 3, we will develop at length some Wittgensteinian arguments regarding the character of normative practices. Here we want to mention another aspect of his philosophy that has taken a longer time to digest by the philosophical and scientific community. Both in his early and late work, Wittgenstein rejected the continuity between philosophy and empirical research. The most influential forms of naturalism (those inaugurated by Quine's claim that epistemology was a branch of psychology) do precisely the opposite. Nevertheless, at the core of Wittgenstein's misgivings about the relevance of empirical research for philosophy there is a deeply naturalist thought: we are natural beings that relate to reality by means of a number of mutually irreducible games, the descriptive, empirical one being one amongst them. Other language-games do not refer to special, non-natural entities, but play different functions: evaluating, giving orders, asking questions, making inferences, joking, expressing our thoughts and feelings, coordinating our activities and so on. To model every language-game on the natural sciences is, in the words of Austin (1962), to fall on a descriptive fallacy.

The conception of philosophy that follows from this is, against first appearances, highly modest: there is no need to postulate, say, mathematical, logical, epistemological or moral entities that only the philosopher can know. On the contrary, philosophy's only function is to help philosophers (and those under their influence) to escape their own metaphysical constructions, and a method to achieve this end is to do a kind of conceptual analysis that respects our everyday linguistic practices. Highly modest, and yet highly subversive: natural language speakers are the ultimate owners of their form of life and nothing that philosophy says can go against their usage. Furthermore, there is no hidden mystery that gives philosophers the higher moral ground, no moral facts, no moral universal principles, knowledge of which would elevate them over mere mortals. Normative evaluation is neither empirically natural nor sublimely supernatural; it is an expression of natural capacities to make sense of the world. ${ }^{3}$

If we apply this framework to our mental, cognitive vocabulary, we can make full sense of Wittgenstein's discussion of intentionality and sensations: when we talk about someone's beliefs or reasons or pains (be them ourselves' or others') we do not describe internal goings-on or refer to queer, ${ }^{4}$ private entities. We rather situate actions and feelings within a framework that tries to make sense of them. Gilbert Ryle's attack on the myth of the 'ghost of the machine' should be read on the same lines: subtracting the Cartesian ghost should not leave us with a Cartesian machine because one depends on the other. Rejecting dualism should lead us to reject its underlying descriptivism. The fact that Ryle is still read as a philosophical behaviourist is to ignore the centrality of his anti-descriptivism: mental vocabulary does not describe behaviour because it does not describe anything at all.

\section{Enactivism and naturalization of normativity}

Enactivism has always been a strongly biologically based naturalist project. The main aim of this approach 
is to define what it is to be a living being. This endeavour has been recently supported by the modelling of basic biological functions, such as chemotaxis (Egbert, Barandiaran, \& Di Paolo, 2012) or metabolic processes (Barandiaran \& Moreno, 2008). Among the achievements of this approach, perhaps the most important has been the development of a certain understanding of the notion of agency: while evolutionary biology emphasizes natural selection in order to explain biological functions of certain anatomical and physiological parts of agents, certain varieties of enactivism explains biological functions, for example, appealing to the maintenance of the organizational scheme that shapes the agent or the system (Christiansen \& Bickhard, 2002; Saborido, Mossio, \& Moreno, in press). Agency is the product of a set of distinct networked systems that, taken together, enable the emergence of a new entity: the agent as a whole. The first step of this project is accounting for individuality: in the original autopoietic formulation, an agent is understood as composed of a series of internal processes that, once assembled, generate a certain type of stability that does not depend on external factors. However, one of the advantages of $\mathrm{Di}$ Paolo's $(2005,2009)$ version of enactivism is that his theory emphasized how the environment plays a fundamental role on the constitution of agency, because processes in which the agent as a whole interacts with its outer environment also contribute to the maintenance of the agent (metabolism, etc.) and help to understand key concepts in the enactivist view, such as 'sense-making', 'viability' or 'adaptivity'. However, external factors cannot determine, in a strong sense, the agent's operation or activity. Thus, the result of its own regulation is the generation of a unity separated from the outer environment (Thompson \& Stapleton, 2009). These self-assembled systems that establish their own individuality are networked via recursive interactions among them, and this fact accounts for the inner sustainability of the agent as a whole. The product of these assembled networked processes (metabolic, nervous, circulatory, etc.) is a full biological agent, which is able to keep its own autonomy through space and time. ${ }^{5}$ This shaping is what Varela $(1979,1997)$ defined as the operational closure of the system: there is no primary system for constituting agency; on the contrary, if we want to analyse the enabling conditions of agency and the roles of the different systems, we will be guided from one to another until realizing that all of them are mutually supportive. ${ }^{6}$ This leaves the agent in a situation of precariousness (De Jaegher \& Di Paolo, 2007): without this special regulative organization, the same processes of the different systems would tend to dissipate under the same physical conditions. If some of the interdependencies cease to produce their own outputs required by other processes, there could be a propagation of dysfunction that may reduce or destroy the viability of the system (Christensen \& Bickhard, 2002).
Thus, if all this regulative organization or assembly of systems is what allows for the viability of the higher system (the agent), we can claim that the product of this assembly becomes a condition at the same time: the recently emerged agent needs to keep its own individuality in order to survive. This is the sense in which there is room to talk about biological normativity: the agent is produced by itself, and its goal (and also the goal of every subsystem) consists in maintaining its own self-production. As it is claimed, "[s]elf production is a process that becomes a unity and a norm: to keep the unity going and distinct' (Di Paolo, 2005, p. 434). Now we can understand why an agent is an autonomous system: because there is a co-emergence of its own individuality (auto) and normativity (nomos) -which is nothing but to ensure its own identity through time. At this point, we can define a biological notion of normativity: the one related to self-production and autopoiesis, which is highly related to autonomy, being the one that shapes agency (all along with individuality and asymmetry, as explained in Barandiaran et al., 2009).

This normativity of biological processes is also present in cognitive phenomena. This autopoietic or purely biological self-productive normativity is not identical to the normativity of cognition, although it is necessary for it. Within this perspective, cognition, as any other biological process, is part of the set of functions that shape agency and contribute to preserving it. Cognition is explained as an agent-environment coupling in which perception, rather than being a matter of logical computation, is understood as adaptive behaviour (the online and spatiotemporally extended regulation of the agent as a whole with its own environment). This agent-environment coupling is understood as a sensorimotor loop by which every action of the agent produces a different sensation (Varela, Thompson, \& Rosch, 1991). Some loops are more useful for the stability of the agent than others, and those become more salient or meaningful. Thus, within the history of this framework, classical and internalist enactivism (Maturana \& Varela, 1980) was extended in order to include the situated aspects of action and perception that contribute to the current enactivist view of agency (Di Paolo, 2005).

\section{I Adaptivity and sense-making}

Unlike early enactivists, autopoiesis is neither the only source of normativity nor the only possible notion of 'normativity' within the contemporary enactive approach. Autopoiesis is a way of defining normativity by an all-or-nothing explanation: if the structural coupling with the environment is maintained even when certain interactions result in perturbations of the autopoietic dynamics with no loss of organization in the system, then everything that does not result in a loss of organization could be valued as something good (or at least 'not bad') for the organism (Maturana, 1975; 
Varela et al., 1991). This is called the 'conservation perspective'. But recent developments showed that the conservation perspective is a very narrow explanation that cannot account for all the normative aspects of the living and the cognitive in the enactive framework. As Di Paolo claims (2005, p. 439, italics added): 'Events that provoke the same regulative response are not meaningfully distinguishable.' So, the normative aspect for addressing meaningful or valuable aspects of the organism's surroundings must be explained in a different way. These authors, instead of an all-or-nothing view on normativity, propose that meaningfully distinguishable aspects are responded to in graded ways. The idea behind sense-making is to account for such valuable or meaningful aspects. Thus, the notion of 'adaptivity', developed by Di Paolo (2005, 2009), offers a new way for understanding sense-making in a much finer way, and also introduces a new notion of normativity within the enactive framework.

Adaptivity is defined as follows (Di Paolo, 2005, p. 438):

A system's capacity, in some circumstances, to regulate its states and its relation to the environment with the result that, if the states are sufficiently close to the boundary of viability,

1. Tendencies are distinguished and acted upon depending on whether the states will approach or recede from the boundary and, as a consequence,

2. Tendencies of the first kind are moved closer to or transformed into tendencies of the second and so future states are prevented from reaching the boundary with an outward velocity.

As we see, adaptivity is 'a special manner of being tolerant to challenges by actively monitoring perturbations and compensating for their tendencies' (Di Paolo, 2005 , p. 438). This new capacity would come, then, in the agent's monitorizing and compensating (regulating) its own behaviour. 'Both elements, self-monitoring and appropriate regulation, are necessary to be able to speak of meaning from the perspective of the organism' (Di Paolo, 2005, p. 438).

Di Paolo's (2005) notion of adaptivity offers a new way to understand the specific normativity that goes beyond the all-or-nothing picture of autopoietic normativity in which there are no meaningful distinctions of the events that surround the system. These meaningful distinctions that the agent is able to discriminate through adaptivity give rise to a new notion: sensemaking. Sense-making is the concept that enactivists use for explaining the elements that became salient, meaningful or valuable in their environments after a considerable number of regulative interactions with them (Thompson \& Stapleton, 2009). A simple unicellular system such as a bacterium develops its own sense-making through, say, different orientations in a sugar gradient. The different movements that the bacterium is able to perform are regulated depending on the concentration of sugar. The bacterium uses the sugar as a source of nutrients, but sugar's edibility is not an intrinsic property: it is only valuable in relation to the agent that takes advantage of it. Thus, sugar becomes valuable for the organism because it is an element of its environment that allows for its sustainability (inasmuch as it provides a nutrient that supplies energy to the agent and thus lets it maintain its autonomy). Those valuable features of the environment have also a normative character - in this case, if the agent does not keep up its relation with environmental sugar it will probably die. Normativity is, then, realized in every biological process. It is stated (appealing to this definition and also to empirical data; Barandiaran \& Egbert, 2013) that an agent such as the bacterium is able to establish and follow its own norm. Hence, sense-making is a common feature of every living being, from bacteria to humans, because every agent, in the words of Thompson and Stapleton (2009), is able to transform its own world into a place of salience and value and, for this reason, sense-making is a normative activity. According to Di Paolo (2005) and Thompson and Stapleton (2009), there are graded norms of vitality because organisms regulate their activity in ways that improves their conditions for autonomy.

By emphasizing the role of active regulations of agents or organisms with their environments, adaptivity suggests that in sense-making there are graded norms of vitality (health, sickness, stress, fatigue, etc.). These graded norms are the product of the continuous regulation of the organism's activity, which improves its conditions for autonomy. Mere autopoiesis, given its conservative character, only concerns the regulations of the states of the agent based on the conditions of viability, transforming its milieu according to the internal norms of its activity (Thompson \& Stapleton, 2009). Autopoiesis only provides a self-distinct physical system that can be the centre of a perspective and a self-maintained precarious network of processes (Di Paolo, 2005, p. 439). In contrast, adaptivity 'allows the system to appreciate its encounters with respect to this [normative autopoietic] condition, its own death, in a graded and relational manner while it is still alive' (Di Paolo, 2005, p. 439). So, the normativity of autopoietic maintenance reveals itself as insufficient for evaluating the events of the environment in a gradual way. For that, we require adaptivity.

Autopoiesis, thus, is insufficient for sense-making if it is not complemented with adaptivity. According to Di Paolo's claim (2005, p. 439), autopoiesis allows for the creation of a system, while adaptivity is the way in which that system is able to value its own encounters with the environment. Here we will talk about (at least) 
two different kinds of normativity: one established by self-construction or autopoiesis, and the other provided by sense-making, which requires autopoiesis and adaptivity. As Di Paolo puts it (2005, p. 438, italics added): 'If sense-making requires the acquisition of 'a valence which is dual at its basis: attraction or rejection, approach or escape' (Weber \& Varela, 2002, p. 117), a sense-making system requires, apart from the norm given by self-construction, access to how it currently stands against the all-or-nothing barrier given by that norm.'

\subsection{From individual to social interaction: participatory sense-making}

Until few years ago, there was not an independent theory in the enactive paradigm for explaining social interaction. But recently, some authors (De Jaegher \& Di Paolo, 2007) propound a new theory within the enactive framework for understanding social interaction in enactive terms. The enactive account of social interaction is known as participatory sense-making. This approach to social cognition uses the key concepts of enactivism's non-social cognition (such as sense-making), or even some enactive biological concepts (such as the operational closure), in order to explain social interaction, which reinforces the naturalist project of enactivism and also provides a new way for linking the biological, the cognitive and the social.

Which is their particular field of study? With 'social interactions', they 'refer to the face-to-face encounters of everyday life. These encounters range from brief and superficial to deep and extensive' (De Jaegher \& Di Paolo, 2007, p. 486). Also, participatory sense-making, through the application of enactive concepts for explaining these social interactions, can account for these encounters in the way this interactive experience is described in everyday language (De Jaegher, Di Paolo, \& Gallagher, 2010, p. 442). The range of interactions they define as 'social' is so wide that they include our social and well-established practices like dancing or talking (De Jaegher \& Di Paolo, 2007, p. 494), and also the interactions that we humans establish with other animals or even with robots (De Jaegher et al., 2010, p. 443). But not all kinds of interaction fall under this concept. For example, bumping into each other on a busy street would not be a social interaction. On the contrary, social interaction seems to require a regulative aspect: 'A conversation about a sponge is a social interaction, because the participants decide upon the topic together, regulate beginning, course and ending of the dialogue, and their autonomy (neither as living beings, nor as conversation partners) is not destroyed in the process' (De Jaegher \& Di Paolo, 2007, p. 493, italics added).
The tools for describing this regulative and interactive process are mathematical, mainly coordination dynamics (De Jaegher \& Di Paolo, 2007). In summary, social interaction is defined as ' $[\mathrm{t}]$ wo or more autonomous agents co-regulating their coupling with the effect that their autonomy is not destroyed and their relational dynamics acquire an autonomy of their own. Examples: conversations, collaborative work, arguments, collective action, dancing and so on' (De Jaegher et al., 2010, p. 441). Thus, with the concept and the range of examples clear, we can move forward in order to understand how these authors provide an enactive explanation of the emergence of social interactions.

In order to explain this unique cognitive phenomenon, the authors claim that social interaction demands a new, independent level of analysis, and that the features that emerge at this level cannot be reduced to its components: 'The interaction process emerges as an entity when social encounters acquire this operationally closed organization. It constitutes a level of analysis not reducible, in general, to individual behaviors' (De Jaegher \& Di Paolo, 2007, p. 492). The words 'as an entity' are very important: this means that there is an ontological and not just a methodological emergence of a new level of explanation. The new entity really possesses the features or properties that enactivists recognize they have, such as certain normative aspect. How do they explain the emergence of this new entity? There are some conditions for this new, social level to emerge: ' $[\mathrm{G}]$ iven $\mathrm{X}$, and a particular situation in which $\mathrm{X}$ occurs, $\mathrm{F}$ is a contextual factor if variations in $\mathrm{F}$ produce variations in $\mathrm{X}, \mathrm{C}$ is an enabling condition if the absence of $\mathrm{C}$ prevents $\mathrm{X}$ from occurring, and $\mathrm{P}$ is a constitutive element if $\mathrm{P}$ is part of the processes that produce X' (De Jaegher et al., 2010, p. 443). If these conditions are fulfilled, the authors claim, then the new entity would emerge and we could talk properly of a new cognitive level describable in enactive terms.

Thus, social interaction is a new emergent level whose autonomy can be accounted for within the enactive approach if we adequately expand sense-making from the individual to the social. As it is explained in De Jaegher and Di Paolo (2007, p. 504):

We do not experience the other-in-interaction as totally obscure and inaccessible, nor as fully transparent (like an object fully constituted by my sense-making activity), but as something else: a protean pattern with knowable and unknowable surfaces and angles of familiarity that shapeshift as the interaction unfolds. Those patterns of change are influenced by my own participation in the emergence and breakdown of joint relational sense-making, hence they are not totally alien. My actions contribute to define the other-in-interaction not so much as my squeezing contributes to the experience of softness of the sponge but rather in ways that do not necessarily settle into a lawful 
relationship. I must alter my actions contextually in order to reencounter the other and in the process, sometimes, be encountered myself when her sense-making unexpectedly modulates my own. This recursive effect on my actions describes the co-modulation of self-in-interaction and other-in-interaction.

As we can see, the enactive picture goes from the biological to the social, and we can find (at least) two different notions of normativity involved. First, the primitive, non-social normativity of autopoiesis and selfproduction; second, the normativity of sense-making, that requires autopoiesis and adaptivity as necessary features for its emergence. This normativity of sense making is found in non-social cognition as well as in social interaction (participatory sense-making).

After this detailed account of the enactive definitions of normativity, in the following sections we will classify both notions of normativity as belonging to the general descriptivist framework. In section 3.1 we develop the non-descriptivist account of normativity and in section 3.2 we offer some Wittgensteinian arguments as a study case that could be applied to this enactive notions of normativity. To support our defence of the nondescriptivist account of normativity we will adapt some classic Wittgensteinian arguments on rule following (Wittgenstein, 1953). We will hold that attributing normativity to the actions of non-social living beings can lead to a confusion of levels of explanation, even if it is done on the basis of their biological responses or on the idea that those responses are grounded on an individual interpretation of the environment (the sensemaking proposed by enactivist authors).

\section{A non-descriptive, normativist approach to mind and cognition}

\section{I Non-descriptivism and non-explicit normativity}

A norm-following approach to cognition needs not be based on the idea of following explicit general rules to guide behaviour. In this sense, it does not need to rely on an algorithmic-based, cognitivist and intellectualist interpretation of what is normativity. Intellectualism (the idea that an agent, in order to act, must compute explicit general maxims or rules in its mind prior to behaviour) was rejected by Gilbert Ryle (1949), one of the leading philosophers of the norm-following explanation of cognition. For that purpose, he made a capital distinction (used in epistemology and philosophy of action since then), between 'knowing-that' and 'knowing-how'. While the know-that approach is used to characterize explicit, discursive or propositional knowledge (such as purely intellectual knowledge, i.e., mathematical or some other theoretical knowledge), the know-how approach to cognition is the one related to action, skilful abilities and perception. This kind of knowledge is not discursive, propositional or explicit. It could be put into words, but a linguistic expression of that way of acting does not exhaust the normative aspect of the know-how knowledge: this normative aspect is expressed in the mastery of the skills or abilities themselves applied to each particular situation. And this coping in every particular situation cannot be exhausted by a linguistic maxim or rule, because that general rule just expresses the general aspects of that particular ability, not the distinctive and particular features that the agent deals with in specific situations.

Often, for explaining how somebody masters a particular ability, we require certain degree of reasonability that, we will argue, comes from the agent's being part of a community of shared practices. Without this requirement, it could be impossible to explain the normative behaviour of an agent, because it is the only way to explain how the agent is acting for reasons. For example, we could claim that somebody exercised her skills in order to fulfil the task, or that she acted in a certain way because she thought it was the best thing to do. Our intentional vocabulary is irreducible for explaining behaviour. It is the most primitive tool that we have to distinguish mere causal triggerings from proper normative actions that bound our behaviour as cognitive creatures.

So, by emphasizing normativity, what we have here is not an intellectualist approach to action and perception similar to the ones endorsed by cognitivism and the GOFAI view of artificial intelligence. This is because, as Travis (2000, p. 210) claims: 'There is no algorithm for reasonableness'. Rather, agents that know how to deal with their environments are able to discriminate the relevant features they have to attend to and also which are the pertinent responses that agents must provide in order to respond correctly to them. This is the difference between a mere descriptive (fact-stating) stance and a normative stance towards the explanation of our actions and perceptions. If we explain our actions normatively, we provide an explanation in terms of abilities and not just in terms of facts. Thus, agents through their abilities can cope with the environment in different ways and moments, and a scientific explanation of each particular execution of the ability cannot exhaust the normative character of their abilities. This is useful for explaining action and perception, but this normative view goes further. There are several philosophical positions that take as their starting point a non-descriptivist norm-following general framework.

Semantic and moral particularism are two interesting examples (Dancy, 1993, 2004; McDowell, 1979, 1998; Travis, 2000). Semantic particularism defends the idea that the semantic contribution of the same term in every speech act depends on the distinctive features of the context in which it is uttered. Moral particularism claims that ethical evaluation is not based on general 
maxims (such as categorical imperatives or universal commandments). Ethical decisions depends on the sensibility of the agent to the specific demands of particular moral contexts: 'Occasion by occasion, one knows what to do, if one does, not by applying universal principles but by being a certain kind of person: one who sees situations in a certain distinctive way' (McDowell, 1979, p. 374). Two actions of the same kind may have radically different moral valences in different situations and no general maxim can capture such contextsensitivity.

Related to particularism, semantic and moral expressivism (Blackburn, 1993; Brandom, 1994, 2001; Frápolli, 2012; Frápolli \& Villanueva, 2012; Gibbard, 1990, 2012), there are claims that not all our statements about the world are descriptive (i.e., they do not state facts of nature); rather, some of them play the function of expressing an evaluative attitude of the agent with respect to certain features of the world. Expressivist views are not only found in semantics and in ethics, but also in broader areas such as epistemology and metaphysics. Huw Price's $(2011,2013)$ approach to naturalism applies this expressivist idea to what he calls 'object naturalism', which he accuses of being descriptive and hence representational. From semantics to metaphysics, anti-descriptivism is a solid and increasingly influential stance towards cognition.

This norm-following and non-descriptivist stance, exemplified in all these views, outlines the primitive character of normativity in order to characterize action and perception. The main feature of non-descriptivism is the primitive character of a non-explicit and nonintellectualist view of normativity. Starting with the work of Ryle (1949) and Wittgenstein (1953), it is one of the most powerful opponents of the traditional, intellectualist, cognitivist and formalist approach to explain cognition in all its levels, from perception and action to language and ethics.

Contrary to non-descriptivism, any descriptivist approach to normativity implies a factualist assumption. Our explanations of cognition are taken to be descriptive, on a par with the explanations of the natural sciences. To describe an agent as being aware of some feature in its environment is to do the same kind of thing as (let us say, in the sciences of the non-living) attributing a certain weight to a subatomic particle or as describing the mechanics of the sodium-potassium pump. For enactivism, cognition is considered a fact, or a process, that is describable by science, and our natural language expressions should be part of an explanation whose statements directly refer to certain scientific facts or properties.

The problem of the descriptivist approach is that this strategy does not suffice to explain the intrinsic normativity of our mental abilities. Then, the task is to clarify what we mean when we claim that certain action has been performed following a norm. One typical conclusion that comes to our minds when we claim that the normative aspects of our abilities are not reducible to describable facts is the intuition that this idea could entail that abilities and skills are spooky entities or processes. But nothing is further from the truth. To put it in Ryle's words (1949/2009, p. 22):

\begin{abstract}
Now a skill is not an act. It is therefore neither a witnessable nor an unwitnessable act. To recognise that a performance is an exercise of a skill is indeed to appreciate it in the light of a factor which could not be separately recorded by a camera. But the reason why the skill exercised in a performance cannot be separately recorded by a camera is not that it is an occult or ghostly happening, but that it is not a happening at all.
\end{abstract}

In Ryle's view, skills or abilities are not identical with the actions or exercises that manifest them, or with any scientifically measurable property or parameter. The point that Ryle highlights is that not every explanatorily relevant discourse is referential (this is, related to a particular set of facts). From a descriptivist point of view, when we claim that some agent possesses a skill (say, the capacity to act in such and such a way, or to infer this from that) we are asserting a matter of fact. In contrast, from a non-descriptivist point of view, when we claim that an agent possesses certain skills, we express an evaluation of a range of situations. Those expressions do not need to describe or stand for certain entities in the world neither they represent them; instead, they evaluate whether the agent that performs an action or makes a statement is satisfying certain criteria of correctness.

The idea that our normative assessments do not play a descriptive role is independent from the complexity of the action under evaluation. In this sense, the problem of scaling up, ${ }^{7}$ important though it is, is a symptom of a deeper malaise: the reason why social norms cannot be grounded on biological, empirically describable, norms is not their greater complexity, but the fact that norms cannot be grounded on facts. As it should be clear by now, the problem of descriptivism about the mind is not merely that the enactivist approach faces insurmountable difficulties when the cognitive complexity escalates, for instance, when the agent is part of a social community. The problem is already there even for minimally cognitive agents: when we say that an agent (for instance, a bacterium) is searching, avoiding, intending or wanting we are not describing the agent, but interpreting, making sense of its behaviour. The difficulty that we want to highlight is not that enactivism is in a position to describe simple agents but lacks the resources when it comes to linguistic creatures, fully introduced into social customs and practices. The problem is a deeper one: understanding any agent's behaviour goes beyond offering an empirical and mathematical account of its movements. 
This is the essence of Wittgenstein's discussion of rule-following. Taking a normative approach to certain phenomena is not searching for normative facts, on a pair with, say, chemical or physiological facts, but taking a kind of stance on behaviour without which (if the normative approach is adequate) we cannot even place our empirical discoveries within any framework. Neither general rules, nor the agreement of the community nor an interpretation of the rule are sufficient to evaluate in terms of normative standards (though they may be necessary for introducing someone into normative practices). We have agential vocabulary to make sense of the living in terms that are not those of the physical sciences. But we do not need to embrace the idea that actions or norms are entities along with atoms, molecules, bacteria or gorillas.

Rules or norms ${ }^{8}$ have been a subject of heated discussion in contemporary philosophy. There are two especially influential landmarks in the debate: Wittgenstein's (1953) rule-following considerations in his Philosophical Investigations and Saul Kripke's controversial interpretation of Wittgenstein (Kripke, 1982). Wittgenstein argues against several targets: amongst them, Platonistic or Kantian takes, that demand general, universal principles or maxims in order to ground particular normative evaluations, and factualist accounts that understand normative statements as descriptions of parcels of reality, laden with normative properties. One thing is clear: Wittgenstein gives a central role to the social in his discussion. $\mathrm{He}$ insists time and time again on practices, training, customs or the impossibility of following a rule privately. A rule cannot be followed only once or only by one agent. However, it is easy to find convincing counterexample to that simple formulation: surely someone can invent, say, a patience or solitaire card game, play it correctly a couple of times and then forget about it. Or Robinson Crusoe, a favourite within the discussion, can give names to the trees in his island and be consistent in his usage. Are these cases of private rule-following? Self-correction, on the other hand, is a common feature of rule-followers. Tired of dripping milk every time that she uses a tetra brik, Mary tries to hold it the other way around and the spilling is over. If the community plays a necessary role for normativity, it does not seem to be to watch over every instance of following a rule, or establishing one. What then?

As we understand him, Wittgenstein's main points are two: (1) normative practices cannot be grounded on normative facts, and (2) a private model of rulefollowing (and norm-establishing) is highly problematic. We have already dwelled on the first issue. Now we will concentrate on the second. What is a private model of rule-following? It is an account of normative phenomena that accepts as normative actions that, as a matter of principle, can only be performed by one agent. Paradigmatic examples in the debate make reference to private, mental entities (pains, intentions, expectations, etc.). Wittgenstein cannot be discarding the possibility that I feel my pain in silence, think about it (for instance, think about what drug to take to ease the pain), take an aspirin and move on without anyone else being involved in the process. What he discards as nonsensical is the idea of private objects of introspection that are, as a matter of principle, beyond the reach of everybody else. If my thoughts and feelings (or my solitaire game, or Crusoe's naming practices, or Mary's tetra brik clever trick) are not sharable, then they are not thoughts, feelings, games, practices or tricks. They do not need to be actually shared; they only need to be potentially shared (susceptible to be shared) by others to count as proper practices or thoughts.

I can establish and follow a rule in solitude. For it to be established or followed privately, in Wittgenstein's sense of privacy, the rule would need to be understood only by me. If no one could be in a position to judge whether I am acting correctly according to the rule that I myself have established, there is no justification to speak about following it. Furthermore, Wittgenstein emphasizes the need to distinguish between 'it seems right to me' and 'it is right'. For a realm to be normative, there must be room for error and correction, but there must also be room for the agent to realize that it has erred. A creature unaware of the possibility of a gap between her actual behaviour and a better option cannot be evaluated in normative terms (think of a twoyear old child using swear words). Sometimes others make us aware of our mistakes, sometimes we realize on our own. But, how does the awareness originate? We claim, following Wittgenstein, that it comes from our being initiated in normative, social practices. Once that we are introduced in them, we may establish and follow practices on our own, without being trained by someone else. The crucial role of the community is not to correct us permanently, but to show us that, sometimes, what seems correct is not correct.

Wittgenstein opposition to what could be called interpretativism shows both his challenges to intellectualist conceptions of rule-following (to follow a rule is to subsume an action under a general principle) and to the private model of rule-following. If normativity were merely a case of acting in agreement with a general maxim, in order to evaluate whether an action is correct or incorrect we would need to offer an interpretation of the rule for the specific case that shows whether there is accordance or disagreement with the rule. But the interpretation itself would still be subject to interpretation, inasmuch as it retains the universality of the rule being interpreted. This point will be made clearer in the next section.

In conclusion, Wittgenstein's account is a definition of the conditions to talk of rule-following and ruleestablishing. As we will see, both are properly understood only within a social framework. In the following 
section, we will analyse Wittgenstein's discussion on what is to establish and follow a rule as a case of study to diagnose the descriptivist and factualist assumption of enactivism regarding normativity.

\subsection{A case study: the Wittgensteinian account on norm-following and norm-establishing}

In this section, we intend to challenge the notion of enactivist normativity taking inspiration from two Wittgenstenian arguments. First, we will focus on the idea that immediate and untrained biological reactions cannot be considered as normative. Then we will question the notion that individual interpretations of certain stimuli are sufficient to be considered as normative responses to them. After that, we will take individual interpretations to be analogous to the idea of sensemaking. Even when the different examples could be considered as equally biologically brute, differentiating between the two of them - the untrained reaction and the individual interpretation - will be useful for highlighting different aspects of normativity that are missed in the enactivist account.

As we have seen, enactivism takes normativity to permeate all biological and cognitive functions. But, from a certain perspective, this supposed normative character of natural reactions fails to satisfy some specific requirements for something to be classified as normative. One of the clearest examples comes from Wittgenstein's Philosophical Investigations (1953), in which the author places us in a situation where somebody is teaching a pupil to count, and the teacher wonders why, after many repetitions, the student is still not doing it correctly. The first explanation of the student's behaviour is always to appeal to his natural reaction, and the distinction between natural reactions and the right course of action that counting demands suggests that we can distinguish between acting according to one's natural dispositions and acting correctly - acting according to a rule. So, following a rule seems to be something much more complex than naturally reacting. If all there is to following a rule were to act according to one's untrained reactions, then there would be no situation where learning could be thought to be necessary to coming to act in the right way.

When we explain the normative character of a skilful activity like counting, we attend only to the right actions that an agent has to perform in order to count. And the rule for counting numbers is different from the rules that guide other actions or practices. We cannot explain the normativity of a certain skill appealing just to the probable role that this skill could play in sustaining the individual. This is why we can take all actions of an agent to be subsumed under the normative label, but this is insufficient to account for the normative aspect of each action or skill.
The other Wittgensteinian example that is revealing in this context concerns the intelligibility of individual interpretations (PI $\S 198-202$ ). When discussing whether acting according to a norm can be understood as offering an interpretation such that the action becomes subsumable by the rule, Wittgenstein comes back to the example of the pupil learning mathematics. After some successful tests that seemed to show that he has mastered the use of the ' + ' sign (all involving numbers smaller than 1000), the teacher asks him 'how much is $1000+2$ ?' The student answers ' 1004 '. When the teacher tells him that this is not the right answer, he defends himself claiming that he is doing exactly what he was told: 'I did as before. Wasn't the rule: add 2 up to 1000,4 up to 2000,6 up to 3000 and so on?' (PI $\S 185)$. The student has managed to provide an interpretation of the rule behind the use of the ' + ' sign that covers all possible uses of the sign and is consistent with all the examples he was exposed to during his learning. It is tempting to say that the pupil can act in accordance with his own criterion. But we will show later why this cannot be a proper account of rulefollowing.

This example parallels the enactivist idea of sensemaking as an explanation of normativity. Sense-making is the interactional and relational side of autonomy because while establishing its own maintenance, the organism establishes a perspective by which its interactions with its environment acquire a normative status (Thompson \& Stapleton, 2009). Every agent develops its own sense-making, which is to say that different aspects of the environment mean something different for every agent. In that vein, the answer of each agent to the same stimulus could be different without any need of error or contradiction. Sense-making, then, can be understood as a particular interpretation of a certain stimuli in the own environment of every agent.

The Wittgensteinian example fits with sense-making examples if it is understood as an agent answering to a certain stimulus in a sui generis way that is valuable to it. In the Wittgensteinian case, a symbolic stimulus $\left({ }^{\prime}+\right.$ ') is interpreted in a way in which the agent as a whole accounts for a linguistic expression. In this sense, the expression of the rule would be the particular behavioural answer to the stimulus. And the enactivist takes this answer to be normative inasmuch as it allows for the stability of the system. Under the enactivist focus, any action or response to a stimulus would be part of the sense-making of the agent, because normativity and sense-making emerge together. And something is valuable in the enactivist sense when it allows for the selfstability of the system. Thus, any action or specific behaviour based on movements of the agent as a whole would be an expression of the rule that allows for the self-maintenance of the agent. This normativity would be found through all kinds of behaviours, from perceptual to linguistic, given that the enactivist framework 
aims to categorize any cognitive function or ability as a biological one. This would mean that the student in the previous example would not be failing to recognize the symbol ' + ' under his own interpretation - that the student has developed a behaviour that allows him to deal with his environment in a way that the student maintains his own stability. But we all know that the individual interpretation of the symbol ' + ' offered by the student is wrong. Following Wittgenstein, we think that an account of normativity based on individual interpretations cannot be satisfactory. In order to illustrate this, we should come back to the Wittgensteinian example to conclude that the explanation given by the student seems deeply paradoxical: if acting according to a rule is no more than interpreting the rule in such a way that the action falls under it (in linguistic or behavioural terms), then every action can be made out to accord with some interpretation of the rule and every action can also be made to conflict with an interpretation of the rule. Then there would be neither accord nor conflict here (no distinction between 'it seems correct' and 'it is correct'). If acting according to a rule was no more than subsuming the action under an idiosyncratic interpretation of the rule, there would be no distinction between right and wrong and, hence, no normativity. The concepts 'right' or 'wrong', which are tightly connected to the concept of 'norm', would be of no use here. So, if everything is a norm, then nothing is a norm at all because nobody could distinguish what is normative from what is not. As Wittgenstein claims in \$201: 'What this shows is that there is a way of grasping a rule which is not an interpretation, but which is exhibited in what we call 'obeying the rule' and 'going against it' in actual cases.' This, applied to the enactivist account of sense-making, would show that there is no room for error in such a narrow view of normativity. Given that isolated interpretations of stimuli are not sufficient to establish a normative framework, we need to conclude that the particular sense-making of an agent (let's say, a bacterium in a gradient of sugar) cannot be categorized as normative. This point is explicitly stated by Wittgenstein: 'Hence it is not possible to obey a rule 'privately': otherwise thinking one was obeying a rule would be the same thing as obeying it' (PI §202).

\section{Future work}

As we argued in section 3.1, the social plays an essential role in norm establishing and norm following within a non-descriptivist view. Once an agent has gone through these learning and training processes, it acquires the capacity to correct itself in certain fields; to apply to itself the criteria shared within a community of agents that perform the practice. That is, norms have an intrinsic institutional character, and they are socially mediated phenomena. Given that non-social agents are not able to establish and follow their own norms and, also, given that in many cases an agent needs to be corrected in order to follow a norm properly, we think that the best explanation of the origins of norms is that they are natural phenomena located at the social level. ${ }^{9}$ By this we mean the level of communities, because it fits with a plausible empirical explanation of the rest of conditions required to talk about any normative sphere: correction, error, training, and the distinction between epistemic states of being right and wrong via sanctions.

It is worth saying that we can also find this assumption about normativity in the work of other philosophers not directly related with enactivism or with philosophy of biology. Hubert Dreyfus (2005; 2007, p. 357) claims that the regulations with the environment, instead of being conceptual, are normative but not contentful. For that purpose, he bases his line of argumentation on the work of phenomenologists like Merleau-Ponty or Heidegger. Thus, we can find the idea of normativity without content which is more closely related to enactivism than to Wittgensteinian normativity. ${ }^{10}$ Dreyfus's problem is, at the end, the same as the enactivists': he is committed to the possibility of private rule following. A review of the normativity of action in anti-representational cognitive science, beyond the scope of enactivism, would be a sensible task that we hope to return to in the future.

Along with these reflections on normativity, there are other features of the enactive approach that are worth analysing. Among these features we can highlight the problem of the mind-life continuum (closely related to the issues discussed in this paper) and the shaping of agency. Enactivism, as we have seen, is a biological account that aims to explain how agents shape themselves without appealing to any extrinsic force, such as natural selection. In that sense, enactivism, instead of following Darwin (1859), is much more related to von Uexküll (1909), the pioneering ethologist. Both enactivism and ethology are concerned with the relations of agents with their environments in a recursive, looping way. This looping relationship of the agent-environment system is also seen in ecological psychology (Richardson et al., 2008).

While enactivism has focused primarily on the inner self-production of agency and on the role that the environment plays in these processes (Wheeler, 1997), we are committed to a much more externalist view of the shaping of agency. Evolutionary biology can explain not only the features of individual agents but also features of populations not by means of inner forces but by means of laws of nature. Also, we understand that this externalism is best supported by the idea of niche construction (Odling-Smee, 2009; Sterelny, 2007), which is suitable for explaining the biological origins and emergence of affordances (Reed, 1996). Thus, on one side, evolutionary biology preserves the externalist account of ecological psychology and explains its 
biological origins; and on the other side, ecological psychology explains by means of the idea of niche construction how perception (affordances, ecological information) exerts selective pressure on biological agents. Although there are enactivist approaches in biology that have been combined with an ecological view of perception (Chemero, 2009, pp. 153-154), we strongly support a purely externalist view of perception and biology endorsed by the evolutionary and ecological approach to explaining the life-cognition connection. First, because it can explain how affordances are a feature not only of individual agents, but also of populations; and second, because it emphasizes the role of the environment in adaptation, which is significantly underestimated within the enactive approach.

In fact, we are far from arguing that the enactivist viewpoint has no place in an anti-representational account of the life-mind continuum; we are only claiming that it is not the only anti-representational theory on the market that is able to explain different aspects of the living. As we have claimed before (Pinedo \& Noble, 2008), a methodological pluralism is able to answer many more questions than a misplaced faith in just one theory or family of theories. In that sense, what we defend is that there are genuine questions, such as 'how is an agent able to keep its own stability through time?, that could be answered by appealing to enactivism. But we believe that it is not healthy for the endeavour of science and philosophy to answer different kinds of questions ('how did this feature evolve?', 'why does this agent behave like that?', etc.) in terms of just one kind of concept, theory or process. This message was clear through this paper in its relation to normativity in action, but it can also be extended in the future to a wider explanation of agency than the one offered by the enactivist authors under review.

\section{Conclusion}

Given that the individualistic perspective of enactivism leads to paradoxical situations and that there is no room for the idea of an individual agent following and establishing its own norms, we have concluded that the necessary conditions for real normativity include reference to a community with shared practices. We have argued that the consideration of normativity as an institutional, socially mediated phenomenon fits very well within the project of naturalizing normativity: normativity is not a feature of particular and isolated individuals, but a way to understand the behaviour of agents as members of populations and communities.

We have argued that, in their effort to offer a unified picture of cognitive processes, enactivism often embraces an approach to normativity that reduces it to a scientifically describable feature of cognition. This amounts to taking normativity for granted as an element that coemerges with individuality and action. We have tried to offer an alternative naturalistic viewpoint that refuses to countenance normative facts and, hence, avoids naturalizing normativity by normativizing nature.

\section{Acknowledgments}

We are thankful to Neftali Villanueva, Seth Bullock and the three anonymous referees from Adaptive Behavior for fruitful comments and discussions.

\section{Funding}

All three authors of this paper were funded by the Spanish Ministerio de Ciencia e Innovación under the research project 'Dispositions, Holism and Agency' (FFI2010-19455).

\section{Notes}

1. In this sense, authors as diverse as Canguilhem (1966), Jonas (1968), Maturana and Varela (1980), Di Paolo (2005), Barandiaran et al. (2009), Nöe (2004), and Varela et al. (1991) can be classified as enactivists in a wide sense.

2. But see his reaction, at the end of his career, to the criticism of retaining an ontological conception of the mind (Ramberg, 2000; Rorty, 2000).

3. Huw Price's distinction between 'object naturalism' and 'subject naturalism' (Price, 2011) is a recent attempt at highlighting the difference between a reductionist project that makes every statement answerable to the empirical discoveries of the natural sciences and a project that stresses the natural character of our explanatory practices. Price links this distinction to expressivism, the view according to which many of our natural language terms (in particular, higher-order concepts that are predicated of sentences rather than of objects: logical constants, evaluative terms such 'it's true that ..., 'it's correct to ..., etc.) play a non-referential role. For a recent defence of expressivism, see Frápolli and Villanueva (2012). See section 3.1.

4. 'Queer' is the term that Wittgenstein uses when he distances himself from the thesis that intentional attributions predicate a relation between an agent and an intentional object (paradigmatically, a proposition). This is just one of the forms that descriptivism about the mind can adopt.

5. Note that the force that shapes what it is to be a biological being is not an extrinsic force or law like natural selection but the inner balance and attraction among the various internal processes (at least in the early stages). Based on this, we can claim that this perspective is much more related to biophysics than to evolutionary biology, because it focuses not on populations but on individuals and their own inner self-emergent balances. This helps us to understand why complex-systems modelling has become in recent years the main tool that provides empirical support to the enactivists' claims, and why this approach is so interested in individual agents rather than in populations.

6. This operational closure implies a thermodynamical openness (Thompson \& Stapleton, 2009). Here we can find, again, the connection with biophysics.

7. We are thankful to an anonymous referee for warning us about the importance of addressing more explicitly the scaling-up problem in this paper. 
8. The term normativity was introduced in the $80 \mathrm{~s}$ in the context of Kripke's (1982) discussion of Wittgenstein's rule-following considerations. In this paper, we use the terms interchangeably.

9. As it has been depicted in previous sections, enactivists consider that there are socially established rules. For example, 'even if the origin of some norms does not fully lie within the individual (e.g., social norms) it is always the individual who internalizes them' (Barandiaran et al., 2009, p. 6). We consider that, based on this quote: (1) there is no need to appeal to any kind of internalization of the rule and (2) we claim that norms can only be socially established. For (2), some arguments have been presented, but for (1), in order to reject the idea of internalization in a rule-following process, it is also interesting to bring up here the Wittgenstenian example of the beetle in the box (PI §293). Let us assume that everyone in their own case knows how to follow a rule because they have internalized it. Each one would walk around carrying a box and calling what is inside 'a beetle'- or, for our own purposes, 'a norm'. Nobody can look inside anyone else's box, and everyone knows what a norm is only through looking inside his or her own boxes. On the other hand, there is no need to look inside our boxes because in our everyday life we all know how to use the concept 'beetle' or 'norm'. Suppose that in fact we all have different things in our boxes, or even imagine that there is nothing at all in them. Just as the object in the box plays no role at all in our understanding of how to use the concept, we do not need to look inside us or to appeal to any inner state in order to know how to follow a rule. This is why we claim that even within this enactivist framework, social norms are not properly depicted.

10. It is worth saying that not all Heideggerians claim that the non-socially mediated and active being-at-hand regulations with the environment are normativity-loaded. For example, Wheeler claims, contra Dreyfus (who classifies the ideas on skilful activity of Heidegger, Merleau-Ponty and Sartre as being normative but not conceptual), that the Heideggerian account of skilful activity cannot be normative in Dreyfus' sense because '[i]n fact Heidegger goes further. For he holds not that culture is $a$ source of normativity, but that the very idea of normativity makes sense only in the context of a culture. For Heidegger, then, the crucial for-the-sake-ofwhich relation - the normatively loaded structure that is at the root of every involvement network and that involves an act of projective self-interpretation - is itself cultural in character' $(2005$, p. 148). In that sense, this interpretation of Heidegger would be much more in line with our Wittgensteinian view than the one offered by Dreyfus (2007).

\section{References}

Austin, J. L. (1962). How to do things with words. Oxford, UK: Clarendon Press.

Barandiaran, X. E., \& Egbert, M. (2013). Norm-establishing and norm-following in autonomous agency. Artificial Life, 20(1), 5-28.

Barandiaran, X. E., Di Paolo, E., \& Rohde, M. (2009). Defining agency. Individuality, normativity, assymetry and spatiotemporality in action. Journal of Adaptive Behavior, 17(4), 367-386. In M. Rohde, \& T. Ikegami (Eds.), special issue on Agency in Natural and Artificial Systems.

Barandiaran, X. E., \& Moreno, A. (2008). Adaptivity: from metabolism to behavior. Adaptive Behavior, 16(5), 325-344.

Blackburn, S. (1993). Essays in quasi-realism.Oxford, UK: Oxford University Press.

Brandom, R. B. (1994). Making it explicit. Cambridge, MA: Harvard University Press.

Brandom, R. B. (2001). Articulating reasons. Cambridge, MA: Harvard University Press.

Canguilhem, G. (1966). Le normal et le pathologique. Paris, France: PUF.

Chemero, A. (2009). Radical embodied cognitive science. Cambridge, MA: The MIT Press.

Christensen, W. D., \& Bickhard, M. H. (2002). The process dynamics of normative function. The Monist, 85(1), 3-28.

Cooke, E., \& Myin, E. (2011). Is trilled smell possible? How the structure of olfaction determines the phenomenology of smell. Journal of Consciousness Studies, 18(11-12), 59-95.

Dancy, J. (1993). Moral reasons. Oxford, UK: Blackwell.

Dancy, J. (2004). Ethics without principles. Oxford, UK: Clarendon Press.

Darwin, C. (1859). On the origin of species. London, UK: John Murray.

De Jaegher, H., \& Di Paolo, E. (2007). Participatory sensemaking. Phenomenology and the Cognitive Sciences, 6(4), 485-507.

De Jaegher, H., Di Paolo, E., \& Gallagher, S. (2010). Can social interaction constitute social cognition? Trends in Cognitive Science, 14(10), 441-447.

Di Paolo, E. (2005). Autopoiesis, adaptivity, teleology, agency. Phenomenology and the Cognitive Sciences, 4, 429-452.

Di Paolo, E. (2009). Extended life. Topoi, 28(1), 9-21.

Dreyfus, H. (2005). Overcoming the myth of the mental: how philosophers can profit from the phenomenology of everyday expertise (APA Pacific Division Presidential Address 2005). Proceedings and Addresses of the APA, 79(2).

Dreyfus, H. (2007). Why Heideggerian AI failed and how fixing it would require making it more Heideggerian. Philosophical Psychology 20(2), 247-268.

Egbert, M., Barandiaran, X. E., \& Di Paolo, E. (2012). Behavioral metavolution: the adaptive and evolutionary potential of metabolism-based chemotaxis. Artificial Life, 18(1), $1-25$.

Frápolli, M. J. (2012). The nature of truth. An updated approach to the meaning of truth ascriptions. Amsterdam, The Netherlands: Springer.

Frápolli, M. J., \& Villanueva, N. (2012). Minimal expressivism. Dialectica 66(4), 471-487.

Gibbard, A. (1990). Wise choises, apt feelings. Cambridge, MA: Harvard University Press.

Gibbard, A. (2012). Meaning and normativity. Oxford, UK: Oxford University Press.

Hutto, D. D., \& Myin, E. (2013). Radicalizing enactivism. Cambridge, MA: The MIT Press.

Jonas, H. (1968). Biological foundations of individuality. International Philosophical Quarterly, 8(2), 231-251.

Kripke, S. (1982). Wittgenstein on rules and private language. Cambridge, MA: Harvard University Press. 
Maturana, H. (1975). The organization of the living: a theory of the living organization. International Journal of ManMachine Studies, 7(3), 313-332.

Maturana, H., \& Varela, F. (1980). Autopoiesis and cognition. Dordrecht, The Netherlands: Reidel.

McDowell, J. (1979). Virtue and reason. The Monist, 62(3), $331-350$

McDowell, J. (1998). Meaning, knowledge and reality. Cambridge, MA: Harvard University Press.

Noë, A. (2004). Action in perception. Cambridge, MA: The MIT Press.

Odling-Smee, J. F. (2009). Niche construction in evolution, ecosystems and developmental biology. In A. Barberousse, M. Morange, \& T. Pradeu (Eds.), Mapping the Future of Biology (pp. 69-91). Berlin, Germany: Springer.

O'Regan, K. (2011). Why red doesn't sound like a bell. Explaining the feel of consciousness. Oxford, UK: Oxford University Press.

Pinedo, M., \& Noble, J. (2008). Beyond persons: extending the personal/subpersonal distinction to non-rational animals and artificial agents. Biology and Philosophy, 23 (1), 87-100.

Price, H. (2011). Naturalism without mirrors. Oxford, UK: Oxford University Press.

Price, H. (2013). Pragmatism, expressivism and naturalism. Cambridge, UK: Cambridge University Press.

Richardson, M. J., Fajen, B. R., Shockley, K., Riley, M. A., \& Turvey, M. T. (2008). Ecological psychology: six principles for an embodied-embedded approach to behavior. In P. Calvo, \& T. Gomila (Eds.), Handbook of cognitive science: An embodied approach. San Diego, CA: Elsevier.

Ramberg, B. (2000). Post-ontological philosophy of mind: Rorty versus Davidson. In R. Brandom (Ed.), Rorty and his critics. Oxford, UK: Blackwell.

Reed, E. S. (1996). Encountering the world. Oxford, UK: Oxford University Press.

Rorty, R. (2000) Response to Ramberg. In R. Brandom (Ed.), Rorty and his critics. Oxford, UK: Blackwell.

Rorty, R. (1979). Philosophy and the mirror of nature. Princeton, NJ: Princeton University Press.
Ryle, G. (1949/2009). The concept of mind. New York, NY: Routledge.

Saborido, C., Mossio, M., \& Moreno, A. (in press). Biological organization and cross-generation functions. British Journal for the Philosophy of Science.

Sterelny, K. (2007). Social intelligence, human intelligence and niche construction. Philosophical Transactions of the Royal Society of London, Series B, 362, 1480, 719-730.

Stewart, J., Gapenne, O., \& Di Paolo, E. (Eds.) (2010). Enaction: toward a new paradigm for cognitive science. Cambridge, MA: The MIT Press.

Thompson, E. (2007). Mind in life: biology, phenomenology and the sciences of the mind. Cambridge, MA: The Belknap Press of Harvard University.

Thompson, E., \& Stapleton, M. (2009). Making sense of sense-making. Reflections on enactive and extended mind theories. Topoi 28, 23-29.

Travis, C. (2000). Unshadowed thought. Cambridge, MA: Harvard University Press.

Varela, F. (1979). Principles of biological autonomy. Boston, MA: Kluwer Academic.

Varela, F. (1997). Patterns of life: intertwining identity and cognition. Brain and Cognition, 34, 72-87.

Varela, F., Thompson, E., \& Rosch, E. (1991). The embodied mind. Cambridge, MA: The MIT Press.

Von Uexküll, J. (1909). Umwelt und Innenwelt der Tiere. Berlin, Germany: Springer.

Weber, A., \& Varela, F. (2002). Life after Kant: natural purposes and the autopoietic foundations of biological individuality. Phenomenology and the Cognitive Sciences, 1(2), 97-125.

Wheeler, M. (1997). Cognition's coming home: the reunion of life and mind. In P. Husbands, \& I. Harvey (Eds.), Proceedings of the 4th European Conference on Artifical Life (pp. 10-19), Cambridge, MA: The MIT Press.

Wheeler, M. (2005). Reconstructing the cognitive world. Cambridge, MA: The MIT Press.

Wittgenstein (1953/2001). Philosophical investigations. Oxford, UK: Blackwell.

\section{About the Authors}

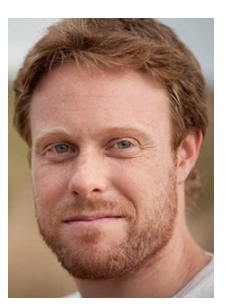

Manuel Heras-Escribano MA logic and philosophy of science (USC, 2010), MSc neurosciences (UAM, 2012), is a PhD student at the department of philosophy 1, Universidad de Granada (Spain). His thesis is focused on a conceptual analysis of affordances.

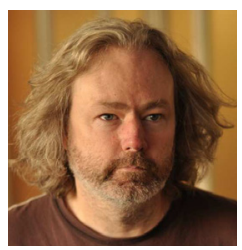

Jason Noble PhD cognitive science (University of Sussex, 1998) was a senior lecturer at the faculty of electronics and computer sciences, University of Southampton (UK). His research is focused on the evolution of communication and social learning via agent-based modelling and artificial life. 


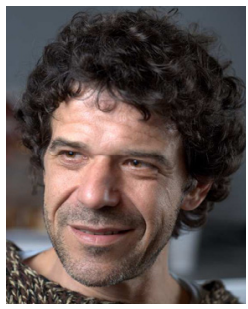

Manuel de Pinedo PhD cognitive science (University of Sussex, 2000) is tenured professor at the faculty of philosophy, Universidad de Granada (Spain). His research is focused on the philosophy of mind and epistemology from a pragmatist and post-ontological perspective. 